$\begin{array}{ll}\infty & l \\ 0 & 0 \\ y & 1 \\ 0 & n \\ \# & \# \\ 0 & y \\ 0 & d\end{array}$

\title{
4 \\ NODAL ANALYSIS OF STIRLING CYCLE DEVICES
}

Alfred Schock

Fa1rchild Space and Electronics Company Germant own, Maryland

ABSTRACT

This paper describes a general-purpose program for the nodal analysis of Stirling-cycle devices or other cyclic regenerative machines, and presents an extensive discussion of results for an illustrative problem. The program employs finite-difference, explicit-forward solutions, and is readily adaptable to various machine topologies. The machine is divided into specifiable numbers of fluid and solid nodes. The program solves the gas-dynamic differential equations (mass, momentum and energy balances) for each fluid node, and an energy balance for each solid node. Interactions between these are represented by heat transfer and fluid friction terms. The kinetic energy of the fluid and the Inertial resistance to flow acceleration are accounted for Leakages through seals and ports are included in the analysis. special schemes for enhanced mathernatical stability and for accelerated convergence to a steady-state cycle are employed. The program is applicable to both disciplined-piston and freepiston engines. It can automatically generate very detailed outputs, both tabular and graphic (Eulerian, LaGrangian, and 3-dimensional) to help provide insight and understanding. Extensive illustrations and discussions are presented.

SNAP (STIRLING NODAL ANALYSIS PROGRAM) is a digitai computer program designed to provide detailed

analyses of Stirling-cycle devices, such as Stirling engines or refrigerators. The program was developed by Fairchild Industries under a contract from the "Department of Energy's Division of Mdvanced Systems and Materials Production, in conjunction with a parallel free-piston Stirling engine development contract to Mechanical

Technology, Inc. [1]*.

Space limitations in the present paper do not permit a detalled description of the analytical nodel and mathematical methods used in the SNAP program. Those subjects are discussed in detail In a separate and much longer paper [2]. That paper presents the basic set of simultaneous partial differential equations, their converalon Into fintte-difference form, and the leapfrog Integration technique used for solving those equations. It describes a numerical stability problem, and two stabilization methods which uccessfully overcame that problem. The paper Aso describes two separate acceleration schemes for speding up convergence to a steady-state cycle.

The present, brief paper contains only a gunlitative description of the analytical cethodology employed. This is to permit adequate sace for a detailed presentation and disussion of the computed results for a typical stirling-engine problem.
Like earlier programs (e.g., [3]), the SNAP program employs finite-difference equations to model the behavior of a Stirling engine. It uses explicit-forward solutions, and is written in Fortran, to permit easy modification and adaptation to various machine topologies.

The machine's fluid passages are represented by a one-dimensional nodal string, consisting-in sequence--of a single expansion-space node, specifiable numbers of heater nodes, regenerator nodes, and cooler nodes, and a single compressionspace node. In addition to the above working fluid nodes, there are corresponding parallel strings of metal wall nodes and regenerator matrix nodes. Interactions between adjacent fluid nodes and metal nodes are represented by appropriate heat transfer and fluid friction terms.

A typical example of such an array, with a total of 25 working space nodes, is illustrated schematically in Figure 1 . Nodes 26 and 27 represent gas springs required for resonant piston and displacer motions in the free-piston engine to which the program was applied.

Fig. 1

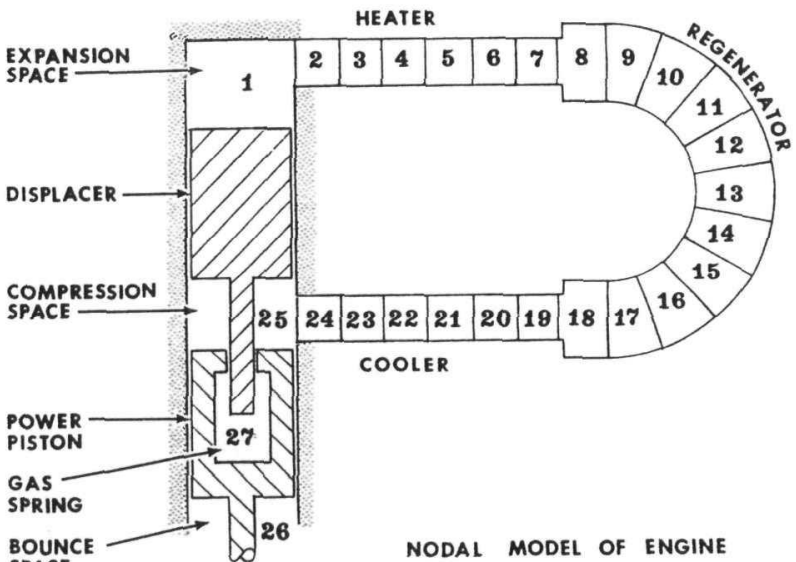

For each gas node, the program solves the full set of fluid dynamic equations, consisting of mass, momentum, and energy balances. The energy balance includes a kinetic energy term, and the momentum balance accounts for sudden expansion and contraction losses, and includes a term accounting for inertial resistance to fluid acceleration. No other program incorporating those terms was available in the public literature at the inception of this study. This is no longer so, since the

end of paper.

1771

SAE/P-78/75/\$02.50

Copyright (C) 1978 Society of Automotive Engineers, Inc. 


\section{DISCLAIMER}

This report was prepared as an account of work sponsored by an agency of the United States Government. Neither the United States Government nor any agency Thereof, nor any of their employees, makes any warranty, express or implied, or assumes any legal liability or responsibility for the accuracy, completeness, or usefulness of any information, apparatus, product, or process disclosed, or represents that its use would not infringe privately owned rights. Reference herein to any specific commercial product, process, or service by trade name, trademark, manufacturer, or otherwise does not necessarily constitute or imply its endorsement, recommendation, or favoring by the United States Government or any agency thereof. The views and opinions of authors expressed herein do not necessarily state or reflect those of the United States Government or any agency thereof. 


\section{DISCLAIMER}

Portions of this document may be illegible in electronic image products. Images are produced from the best available original document. 
publication of an excellent PhD thesis by I. Urieli at the University of Witwatersrand, South Africa [4].

An alternative program in which inertial forces are ignored was also developed, as explained in Reference [2]. That program, in effect, assumes instantaneous quasi-equilibrium between the local pressure gradient and fluid flow rate. It provides equally detailed though less accurate results than the full inertial program, but its operating speed is one to two orders of magnitude higher. The loss in accuracy depends on machine dimensions, operating frequency, and other design parameters, and its magnitude can only be assessed by ultimate comparison of results from both programs for the same design.

While the analysis discussed in this report deals with an engine with prescribed piston and displacer motions, the program has also been applied to a problem with free-piston dynamics, in which the displacer and piston motions are purely the result of forces exerted by the gas and the 1 oad response.

\section{PROGRAM STRUCTURE}

Both programs consist of a pre-processor, a main program, and a post-processor. The preprocessor inputs the basic machine dimensions, fluid and metal properties, the desired numbers of nodes for the heater, regenerator, and cooler, and the operating parameters and initial conditions*. From these inputs it computes the length, cross-sectional area, wall and matrix surface areas, and wall conductance for each node; and also initializes the fluid parameters in each gas node.

Starting from the above values, the main analysis program carries out the required integration of the simultaneous differential equations, stores the computed time-and space-dependent results for postprocessing, and extracts the desired summary information, such as cyclic heat flow, energy balance, power output, and efficiency.

Finally, there is an extensive postprocessor program which prepares output tables that summarize the problem parameters, the computational parameters used, and the computed results. Most important, it automatically prepares a very wide variety of graphic outputs, in Eulerian, LaGrangian, and 3-D formats. These graphic outputs, which are made possible by the detalled nodal analysis of this program, are designed to provide insight and facilitate understanding of the engine's operation.

\section{ENGINE GEOMETRY}

Computer-generated output for a typical disciplined-piston problem is presented in

* For most of our computer runs, the problem was started with a uniform gas pressure, zero flow, and identical 1inear temperature profiles for the regenerator wall, matrix, and gas.
Figures 2 through 21. Figure 2 presents a summary table which defines the physical problem and its mathematical representation. It is a "fresh-start" problem; i.e., not a continuation of an earlier problem. (Such restart capability exists in the program). The problem deals with a two-piston single-cylinder machine, with the machine dimensions and prescribed piston motions defined below:

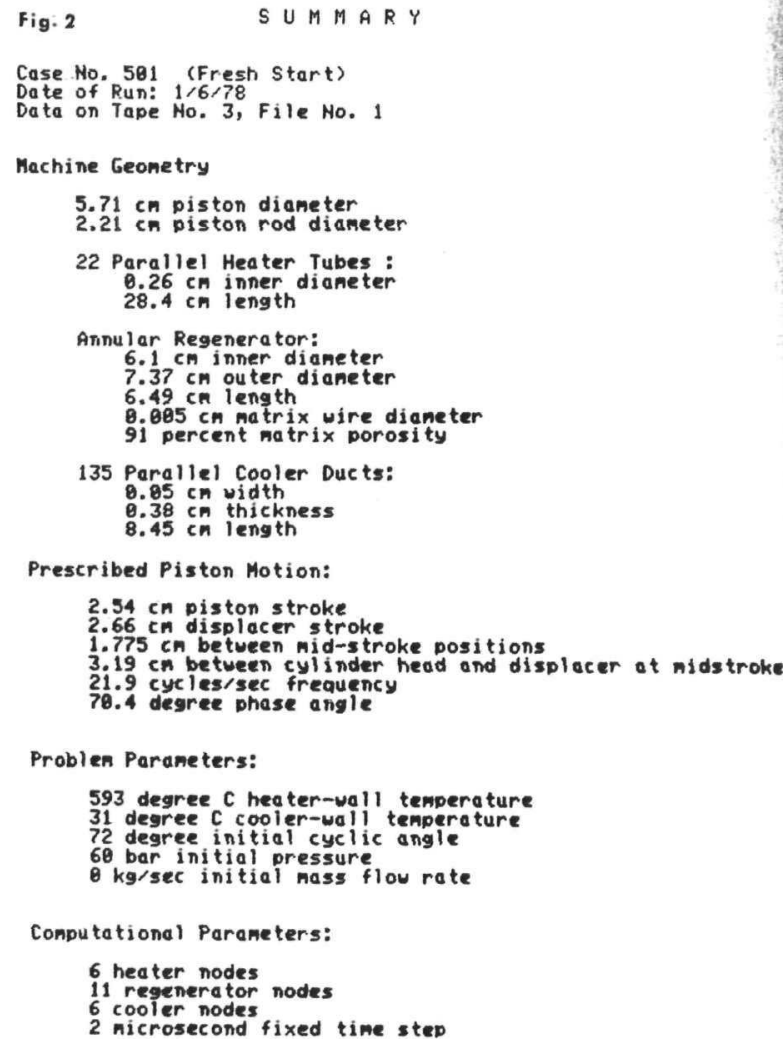

A schematic view of the machine topology and of the nodal arrangement was presented earller in Figure 1. Although that flgure shows only a single string of gas nodes, in the actual machine there are 22 parallel heater tubes and 135 parallel cooler ducts. These are connected to a single annular regenerator, filled with a wire matrix of $0.05 \mathrm{~mm}$ dlameter and having a matrix porosity of $91 \%$.

The power piston has a stroke of $2.54 \mathrm{~cm}$, and the displacer stroke $182.66 \mathrm{~cm}$. The two pistons move with a frequency of 21.9 hertz, and the displacer leads the piston by a phase angle of 70.4 degrees. W1th both p1stons at the $1 \mathrm{r}$ midstroke position, there is a gap of $1.775 \mathrm{~cm}$ between the two plstons, and a gap of $3.19 \mathrm{~cm}$ between the displacer and the cylinder head. In addition to the volumes which can be swept by the pistons, there is a residual volume of 4.0 cc in the expansion space when the displacer meets the cylinder head; and a residual volume of $23.5 \mathrm{cc}$ in the compression space when the two pistons meets.

The prescribed piston motions are 1llustrated in Figure 3. The lower curve represents the power piston, the middle curve the displacer piston, and the upper bold line represents the cylinder head. The expansion space lies between 
the displacer and the cylinder head, and the compression space between the power piston and the displacer. As can be seen, during one part of the cycle the power piston and displacer almost touch and the compression space almost vanishes (except for the residual volume).

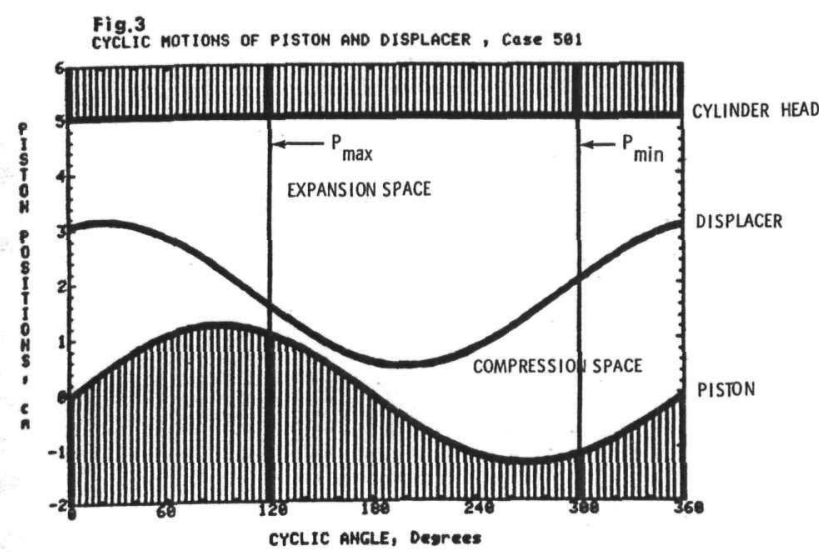

Finally, the problem considers both continuous-flow leaks, through piston and piston rod seals, and periodic leaks, through centering ports*. The continuous leakage takes place through four annular seals, whose dimensions are tabulated below:

\begin{tabular}{|c|c|c|c|}
\hline Seal Between: & $\begin{array}{r}\text { Dia- } \\
\text { meter } \\
(\mathrm{cm}) \\
\end{array}$ & $\begin{array}{l}\text { Length } \\
(\mathrm{cm})\end{array}$ & $\begin{array}{r}\text { Gap } \\
\text { Width } \\
(\mathrm{mm}) \\
\end{array}$ \\
\hline $\begin{array}{l}\text { Expansion and } \\
\text { Compression Space } \\
\text { Compression and }\end{array}$ & 5.71 & 0.965 & 0.0244 \\
\hline $\begin{array}{l}\text { Bounce Space } \\
\text { Compression and }\end{array}$ & 5.71 & 4.876 & 0.0231 \\
\hline $\begin{array}{l}\text { Bounce Space** } \\
\text { Gas Spring and }\end{array}$ & 2.21 & 3.49 & 0.0203 \\
\hline Bounce Space** & 2.21 & 2.04 & 0.0203 \\
\hline
\end{tabular}

\section{RROBLEM DEFINITION}

As shown in Figure 2, the problem was started Wth a uniform pressure of 60 bars, with the luid Initially at rest in all nodes, and with an intial cyclic angle of 72 degrees. This was a arbitrary choice. The fluid-flow solutions rapidly home in on a steady-state cycle, regardless of starting angle and initial flow rate. Figure 2 also shows a wall temperature of $592^{\circ} \mathrm{C}$ for the heater and expansion space; and a wil temperature of $31^{\circ} \mathrm{C}$ for the cooler and copression space. Initially, the regenerator wall

Buch centering ports are required in freeplston englnes, to prevent the displacer and piston motion from drifting off their desired mid-stroke positions.

We the center of the piston rod seal, there is - circumferential groove, which is connected to the bounce space (not shown in Figure 1). and matrix were assumed to have a linear temperature gradient between their hot and cold ends.

In general, the program treats the temperatures of the hot walls and cold walls as fixed, and allows the temperatures of the regenerator's wall nodes and matrix nodes to float. Occasional$1 y$, the program was run with floating heater wall temperatures, with prescribed heat input rates.

The above problem was analyzed using the methodology described in detail in Reference [2]. This consisted of an inertia-less analysis (25 accelerated cycles plus 2 unaccelerated cycles) followed by an inertial analysis for an additional two cycles. The final results of the two analyses were in good agreement. The results for the last cycle of the inertial analysis are depicted in Figures 4 through 21 .

\section{CYCLIC PRESSURE PROFILES}

The piston motions shown earlier in Figure 3 produce the cyclic pressure variation depicted in Figure 4. Actually, that figure presents seven different curves, representing pressures at different locations ranging from the expansion space to the compression space. However, these curves are so close together as to be indistinguishable on the scale of the figure. In other words, at the prescribed operating frequency of $22 \mathrm{~Hz}$ the spatial variation of pressure is very small compared to its temporal variation.

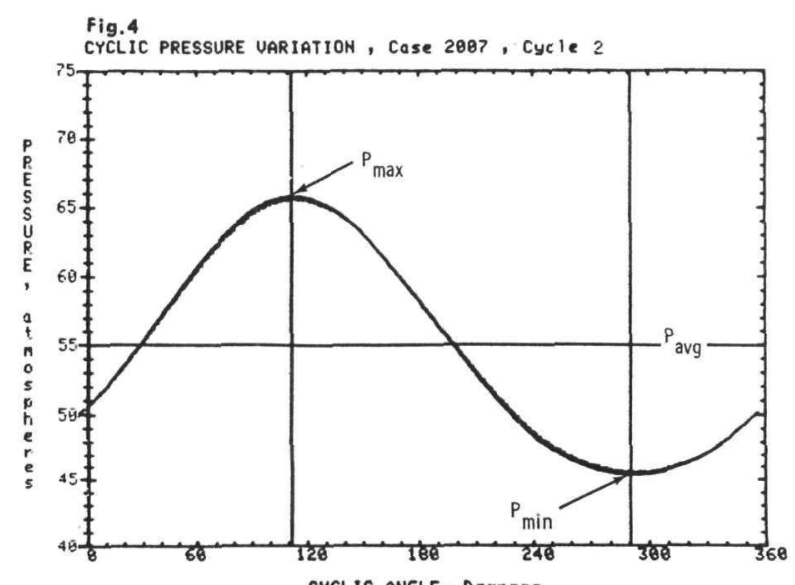

The two vertical lines in Figures 3 through 11 depict the points of maximum and minimum pressure. As shown in Figure 3, these are close to the points of minimum and maximum gas volume. However, they do not quite coincide, because of changes in the mean gas temperature. As can be seen, the pressure wave lags the power piston motion by 30 degrees.

Figure 5, shows the cyclic variation of the pressure difference between various gas nodes and the center of the regenerator. These pressure differences include the friction losses, the expansion and contraction effects at the ends of the heater and cooler, and the acceleration and deceleration forces required to overcome the fluid's inertia and cause the changes in fluid flow rates. 
Fig.

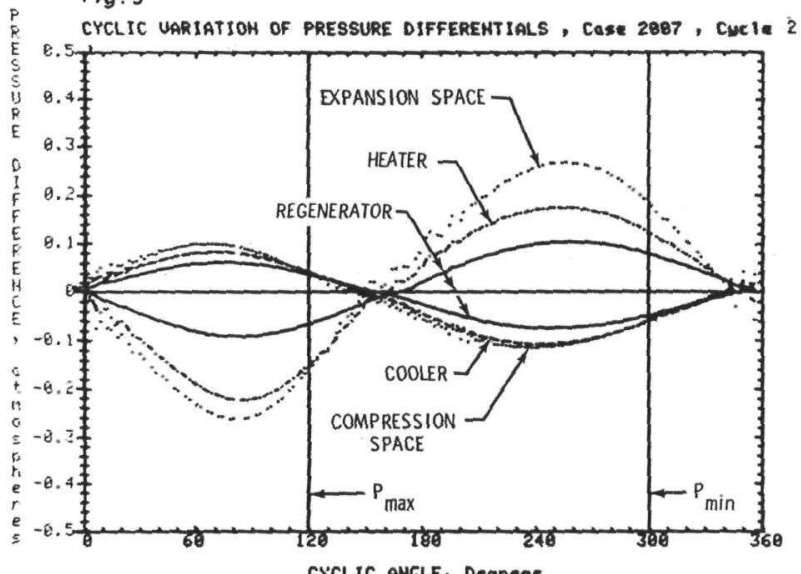

CYCLIC MASS-FLOW-RATE PROFILES

The resultant cyclic variation in mass flow rates is shown in Figure 6 for nine different node boundaries: expansion space $(1 / 2)$, heater $(5 / 6)$, regenerator $(9 / 10,11 / 12,13 / 14,15 / 16$, $17 / 18)$, cooler $(21 / 22)$, and compression space $(24 / 25)$.

When a problem is first started from arbitrary initial conditions, the solution exhibits rather violent startup oscillations, but these die out surprisingly fast. By the second half of Cycle 1 the eventual flow pattern is quite well established. It is noteworthy that the initial start-up oscillations have a period approximately equal to the round-trip transit time of a sound wave through the total gas passage. Sometimes these sonic oscillations, in much milder form, also make a brief appearance during the steadystate cycle, after reversals of the fl ow dire.

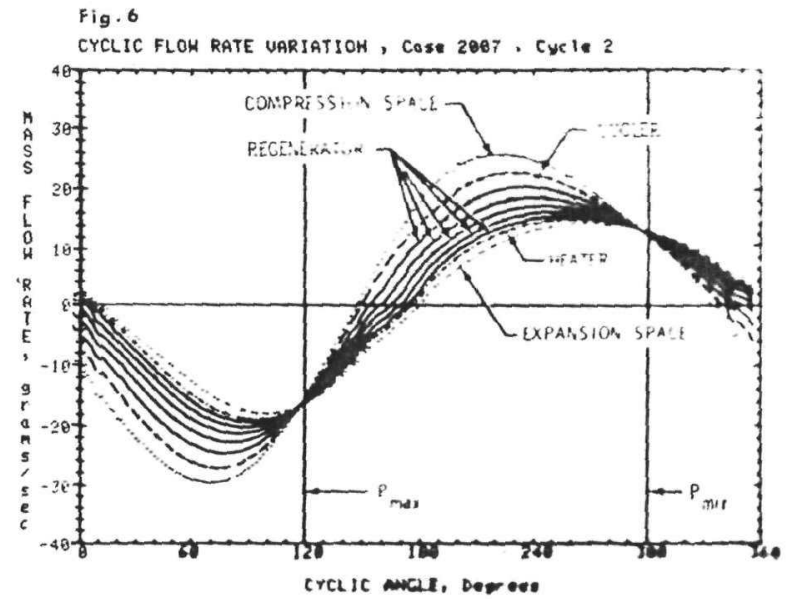

Figure 6 shows that for all points in the engine, the period of positive flow (hot end to cold end) exceeds the period of negative flow. The curves show that, most of the time, the mas flow rate is far from uniform. In fact, there are times when positive and negative flows coexist. For example, at a cyclic angle of $155^{\circ}$, the gas volume is expanding and the pressures and densities are decreasing rapidly. As a result, gas is streaming out of both ends of the regenerator. The reverse situation exists at a crank angle of $350^{\circ}$.
As can be seen, flow reversal (in either direction) starts at the compression-space end and proceeds toward the expansion space. are two points in the cycle when all mass flo rates are approximately equal. These occur nea: the points of maximum and minimum pressure, whes the nodal gas densities are not changing.

\section{CYCLIC TEMPERATURE PROFILES}

Figure 7 shows the cyclic variation of gas temperatures in the expansion space, in two heat nodes $(3,6)$, five regenerator nodes $(9,11,13$, $15,17)$, two cooler nodes $(20,23)$, and the compression space; as well as the variation of matrix temperatures at the same five regenerator locations. Heater and cooler wall temperatures are also shown in the figure.

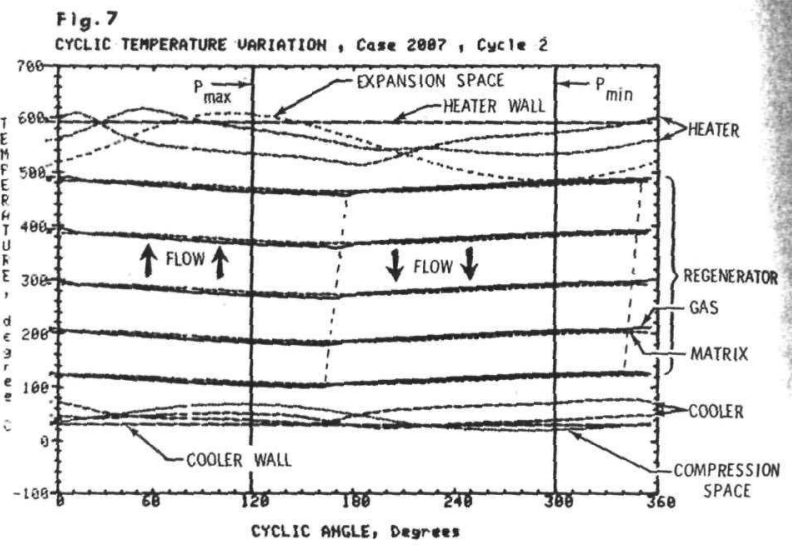

The expansion and compression space temperature variations are primarily due to compression and expansion effects. Both temperatures reach a maximum near the time of maximum pressure, and a ninimum near the time of minimum pressure. $\therefore$ ince heat transfer rates to the expansion and $\therefore \ldots \pi, \pi$ ssion space walls are relatively small, :rese spaces are close to adiabatic.

The variations of gas temperatures in the leter and cooler nodes displayed in Figure 7 ow that during part of the cycle the gas in the heater 15 actually hotter than the heater wall; and during part of the cycle, the gas in the cooler is colder than the cooler wall. This is a source of inefficiency, which results from the fact that the thermal coupling between gas and wall in the expansion and compression spaces is relatively weak.

Finally, Figure 7 displays five solid curves, showing the varlation of gas temperature in the -ezenerator (at nodes 9, 11, 13, 15, 17); accompanied by five short-dash curves, showing the variation of matrix temperature at the same five locations. The cyclic variation of the gas temperature and of the matrix temperature is essentially the same at all regenerator locations. During somewhat more than half of the cycle, the gas is hotter than the matrix, and heat is being stored in the matrix. During the remainder of the cycle, the warmer matrix returns the stored heat to the cooler gas. The relative temperature reversals do not occur simultaneously at all locations. In both directions, the temperature 
reversal starts at the cold end and propagates to the hot end.

The two slanting dashed lines in Figure 7 indicate the times of flow reversal at various points of the regenerator. As would be expected, the period of flow in the hot-to-cold direction tends to coincide with the period of matrix heating; and vice versa. But this coincidence is not perfect. In fact, at the time of flow reversals the gas temperatures are moving away from the matrix temperatures, and some time elapses before they reverse direction and cross over to the other side of the matrix temperature. This comes about because, at the time of flow reversal, the flow velocity and heat transfer are very low, and the gs is undergoing virtually adiabatic expansion or compression.

Inspection of Figure 7 reveals that, for the given regenerator design parameters, the eatrix temperatures are far from constant. They undergo quite noticeable periodic swings, as the result of the cyclic heat addition and removal. The temperature fluctuation of the regenerator wall $1 \mathrm{~s}$ much smaller, because of the latter's much lower surface-to-volume ratio. These temperatures have not been plotted, since their cyclic variation would not be discernible on the scale of the figure.

\section{SPATIAL TEMPERATURE PROFILES}

In addition to the gas temperatures' cyclic varlation, it is also of interest to examine their spatial variation at various times in the cycle. Such spatial temperature profiles are displayed In Figure 8 , as a function of nodal position. Thirty-six curves are shown, at intervals of 10 degrees of cyclic angle. To promote clarity, each curve is offset by $15^{\circ} \mathrm{C}$ from its predecessor. Thus, the temperature scale shown is an absolute scale for only the first (i.e., topmost) curve; it is only a relative scale for the other curves.

Fig. 8

CAS TEMPERATURE PROFILES, Case 2007, Cycle

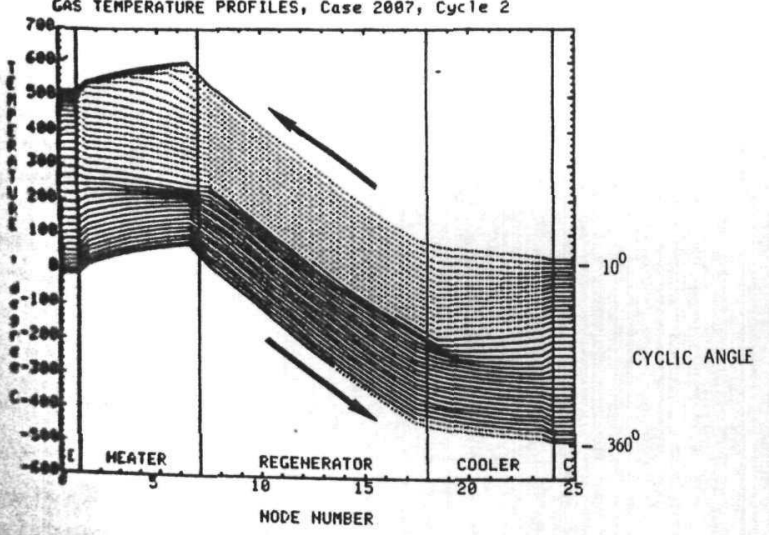

To help interpret the curve, flow from left to $\mathrm{r}$ ight 18 denoted by solid curves, and flow from right to left is denoted by dotted curves. close-spaced curves indicate rising temperatures. ude pacings denote diminishing temperatures. As can be seen, the spatial gas temperature profiles vary cons1derably during the cycle. This is After

ater flow is well established, the gas temper-

eture rises in the flow direction in the heater, and falls in the flow direction in the cooler. This is not true immediately after flow reversal, and some time elapses before the proper temperature profiles are established.

The spatial temperature profiles of the regenerator wall and matrix are presented in an analogous manner in Figures 9 and 10, respectively.

Fig. 9

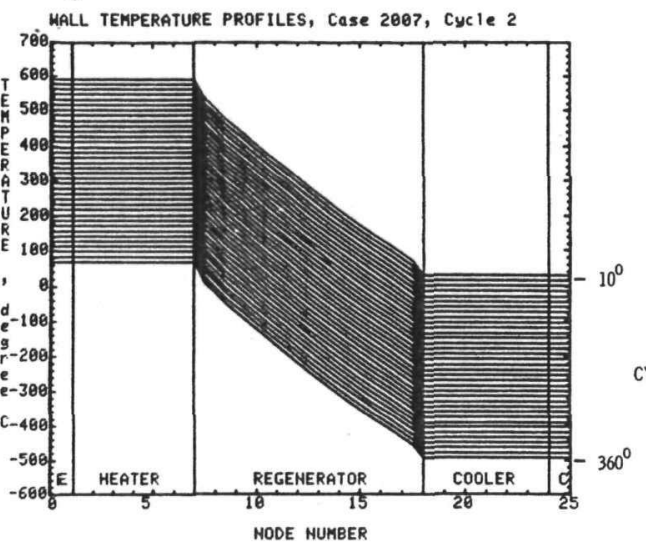

CYCLIC ANGLE

As can be seen, the spatial metal-temperature profiles show much less variation during the cycle than the corresponding gas-temperature profiles. This is because the wall and matrix nodes have a much higher heat capacitance than the gas nodes.

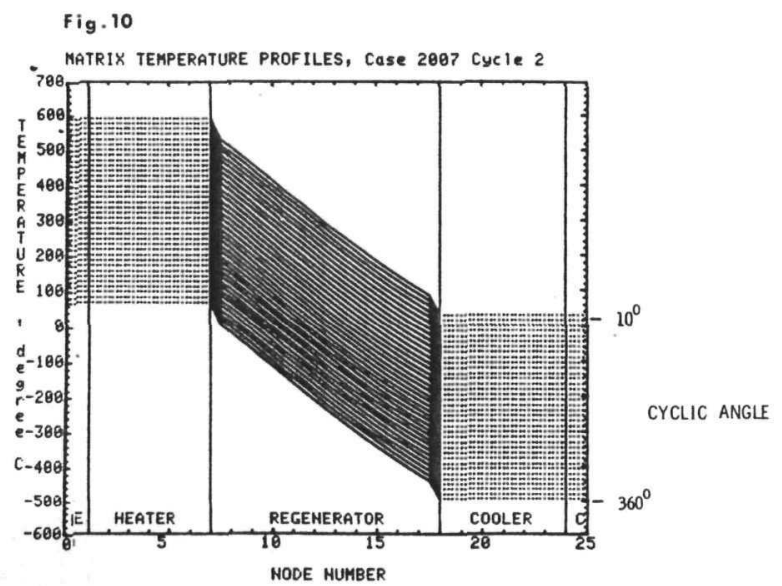

It will be noted that the metal temperature profiles shown in Figures 9 and 10 differ only a little from the initially assumed linear ramps between the hot and cold-wall temperatures. Yet, determination of this small difference, essentially a slight curvature and a small tilt, requires a great deal of computation and is essential for obtaining the steady-state solution.

\section{CYCLIC HEAT-FLOW PROFILES}

Figure 11 shows the cyclic variations of the heat flow rates from various components to the working fluid. The dot-dash curve represents heat flow from the heater and expansion-space wall to the gas; the dashed curve represents heat flow from the cooler and compression-space wall to the gas; and the solid curve represents heat flow from the regenerator (matrix plus wall) to the gas. 
Fig.11

CYCLIC MEAT FLOH UARIATSON, COSE 2887 , CYC IE 2

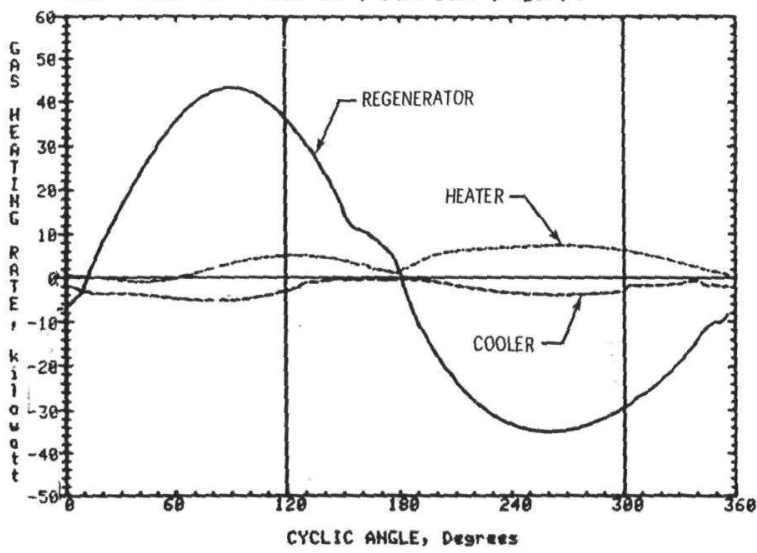

As can be seen, the heat flow to and from the regenerator is much greater than the heat flows from the heater and to the cooler. This is true of any well-designed Stirling engine. Also, we note that all three curves exhibit irregularities at the points of flow reversal, where the local flow velocities (and therefore the heat transfer coefficients) pass through zero. Finally, we see that the matrix-to-gas heat flow is briefer and has a higher peak than the gas-to-matrix heat flow.

\section{MECHANICAL POWER OUTPUT}

Figure 12 presents the pressure-volume diagrams for the expansion space and the compression space, and Figure 13 shows the piston force-vs-position diagrams for the displacer and the power piston.

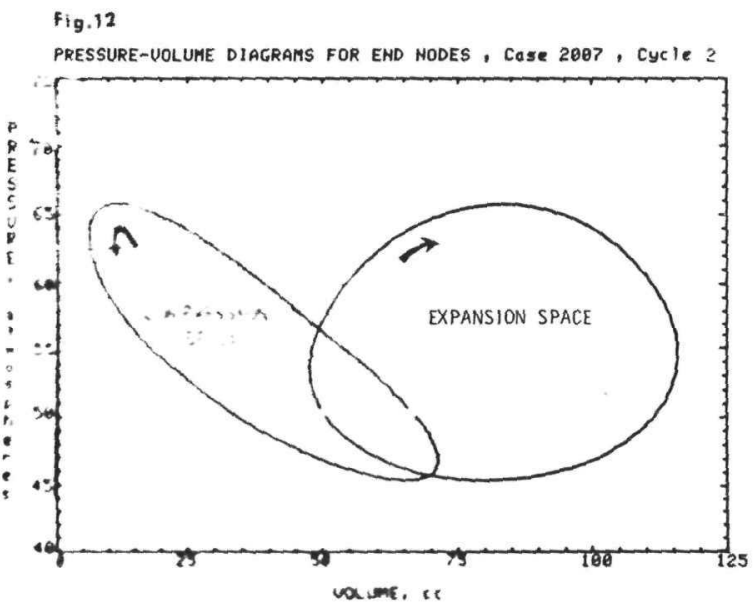

As show by the arrowheads in Figure 12, time varlation is clockwlse along the expansion-space curve and counter-clockwlse along the compressionspace curve. During a cycle, the working fluid does net work in the expansion space, and has work done on it in the compression-space. Since the area enclosed by the expansion-space curve is larger than that enclosed by the compression-space curve, the heat engine has a positive power output. In Figure 13 the force exerted by the working fluid on each piston is plotted versus the piston's position. The area enclosed by each curve represents the work which the gas does on the piston durly
cycle.

Fig. 13

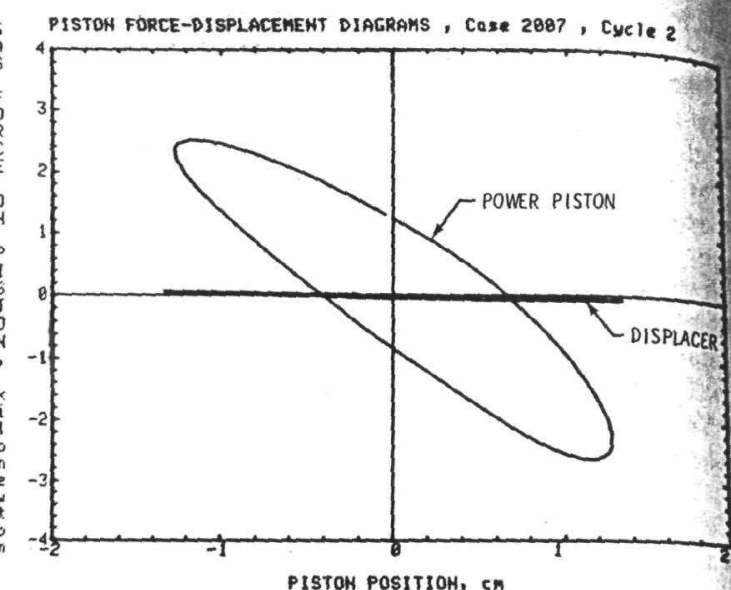

The cyclic motion along the power-piston curv is clockwise, corresponding a net work input from the gas. The area enclosed by the displacer curve is close to zero, as it should be. Virtually all of the mechanical power goes to the power piston, for transmission to the load. The fact that the net force on the displacer is always close to zero shows that the disciplined-piston motions analyzed in this problem are consistent with free-piston operation, since in a free-piston machine the net displacer work must be zero.

\section{ENERGY BALANCE}

The overall energy balance for the above problem is summarized in Figure 14. All cyclic energy changes are expressed as rates of change (in watts) averaged over the cycle.

Fig. 14

ENERGY BALAHCE FOR CASE 1034, CYCLE 50 (Average Flow Rates, in Hatts)

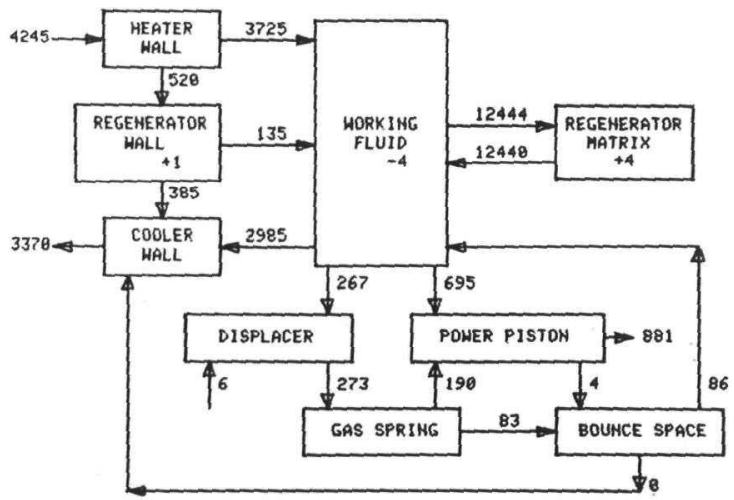

Efficiency $=881 / 4245=28,7 \%$

As can be seen, during the cycle the working gas receives heat at an average rate of 3725 watts from the heater and expansion-space walls, and 135 watts from the regenerator wa11; it loses heat at a rate of 2985 to the cooler and compressionspace walls.

In the same period, the gas sees an average heat flow rate of 12,444 watts to the regenerator matrix and 12,440 watts from the matrix, giving a net heat transfer rate of 4 watts from the gas to the matrix. 
In addition, there is net heat transfer from the bounce space to the compressor space at a rate of 86 watts, averaged over the cycle. This is due to net heat transport as a result of cyclic leakage between those spaces. While the forward and backward mass flows must (and do) balance over the steady-state cycle, the accompanying energy flows need not balance, since the compression space and bounce space can both transfer energy to or from other parts of the system.

Suming the above energy transfer rates, we obtain a net energy input rate to the working fluid of 958 watts, averaged over the cycle.

In the sase perlod, the working fluid does wechanical work at the rate of 207 watts on the displacer and 695 watts on the power plston, for a conbined mechanical output rate of 962 watts.

The difference of 4 watts (or $0.4 \%$ ) between the above sums does not represent a discrepancy in the working fluid energy balance. That energy balance closes much better than 0.4\%. The 4-wat: difference is an indication of how close the rolution $i s$ to the steadystate cycle. other indicators shown in Figure 14 are the rates ath thifor thape of the regenerator wit t 1 witt, or a.s? fnd of the regenerstor soirix ( 4 watis, ve $0.003 \%$ ). The smallness of lien iffferences dewwistrales the effectiven ass of the acceleration schemes in homing in on a stedis-state solution, from arbitrary starting ccriti. ins.

In this connection, it should be pointed out that the 135 watt heat flow rate from the regenerator wall to the working fluid is consistent with steady-state operation. It is balanced by the difference between the 520 watt heat flow from heater wall to regenerator wall and the 385 watt heat flow from regenerator wall to cooler wall.

As mentioned earlier, the working fluid does mechanical work on the displacer at an average rate of 267 watts. This rather large quantity is not a loss to the system, since wuch of it is transferred to the power piston via the gas spring (i.e., the cavity within the power piston shown in Figure 1). Power 1. transferred because of the phase difference between the two pistons.

It was found that in problems with all leakages set to zero, all of the energy which the gas spring receives from the displacer is returned to the power piston. But this is not true for problems with non-zero leakage. As shown 1n Figure 14, of the 273 watts recelved from the displacer, only 190 watts are transmitted to the power piston. The other 83 watts are transferred from the gas epring to the bounce space, as the result of leakage between the two spaces. Again, mass trans fer due to leakage is zero over the cycle, but energy transfer is not. The 83 watts lost to the bounce space is
returned to the compression space via other leaknge paths. While the energy is therefore not lost to the system, it causes a very serious decrease in power output and efficiency, since mechanical energy is converted into low-temperature heat. It was found that, other things being equal, the engine described in this paper would have a power output of 1238 watts without leakage, and only 881 watts with the postulated leakage paths; and a corresponding reduction of system efficiency from $28.7 \%$ to $20.7 \%$. This demonstrates the importance of reducing the seals' gap widths to the lowest possible values, since leakage is proportional to the cube of the gap width.

\section{LAGRANGIAN OUTPUT GRAPHS}

As mentioned earlier, once a given problem has been analyzed by the Eulerian SNAP program, the results obtained can readily be used to generate a family of LaGrangian plots. Such plots are in Figures 15 through 19, for the same problem as presented earlier.

In Figure 15 the nodal positions of specific gas particles are plotted as a function of the cyclic angle. The heater, regenerator, and cooler are shown as fixed nodes ( 1 through 24). The expansion and compression spaces are depicted as variable nodes (of arbitrary scale), to represent their volume variation as the result of piston and displacer motions during the cycle. These volume variations cause the gas particle motions represented by the curves.

$$
\text { Fig.15 }
$$

MOTION OF GAS PARTICLES, Case 2007 , Cycle 2

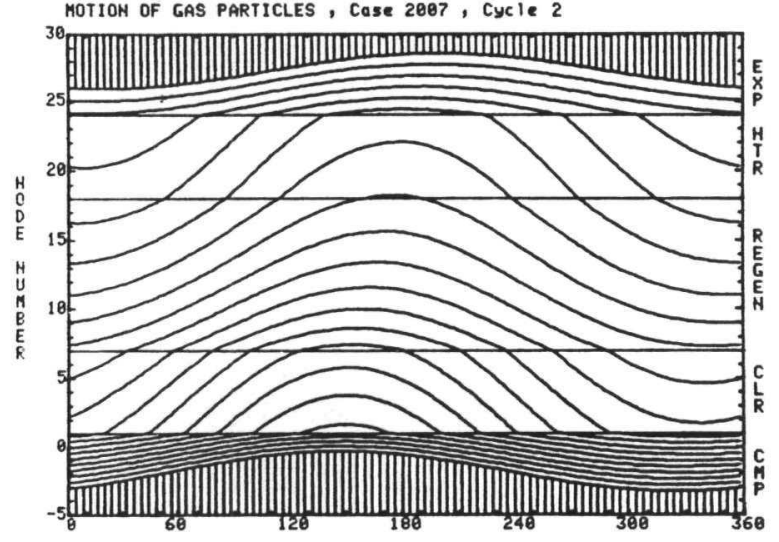

CYCLIC ANGLE, Degrees

The figure presents the nodal paths of 19 gas particles, at intervals of $5 \%$ of the total gas mass in the working space. Thus, the band between any two neighboring curves represents $5 \%$ of the working fluid. As can be seen, about $20 \%$ of the working fluid never leaves the compression space; and approximately $10 \%$ never leaves the expansion space. No single gas particle moves all the way from the expansion space to the compression space. In fact, for the problem at hand, no single gas particle traverses the entire regenerator during the cycle. One of the gas particle paths shown never leaves the regenerator.

Figure 16 shows the cyclic temperature history of some of the gas particles whose motion was depicted earlier in Figure 15. To help interpret the curves, a solid curve is used when the particle is in the regenerator, a dashed curve when the particle is in the heater or cooler, and a dotted curve when the particle is in the expansion or compression space. (Curves for the three coldest and two hottest gas particles have been omitted for clarity.) 
Fig. 16

TEMPERATURE VARIATION OF GAS PARTICLES, CASE 2007 , CyC Ie 2

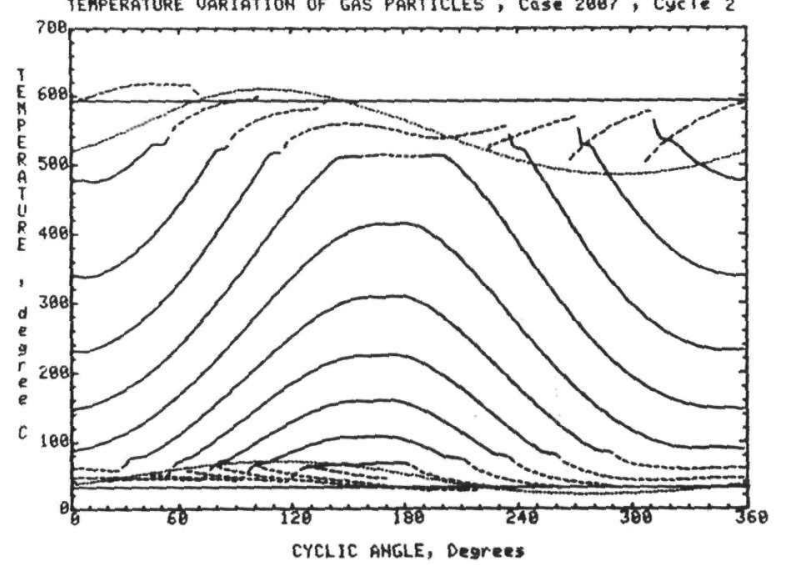

The figure clearly shows that gas particles traveling in the regenerator are alternately heated and cooled (depending on the direction of motion). Particles traveling through the heater are almost always heated, regardless of direction. The only exceptions are at a cyclic angle around 90 degrees, where the gas is hotter than the heater wa11; and around 170 degrees, where the cooling effect due to expansion is greater than the heating effect of heat transfer from the wall. The dotted curves show the strong expansion and compression effects while the gas particles are in the almost adiabatic end nodes.

Fig. 17

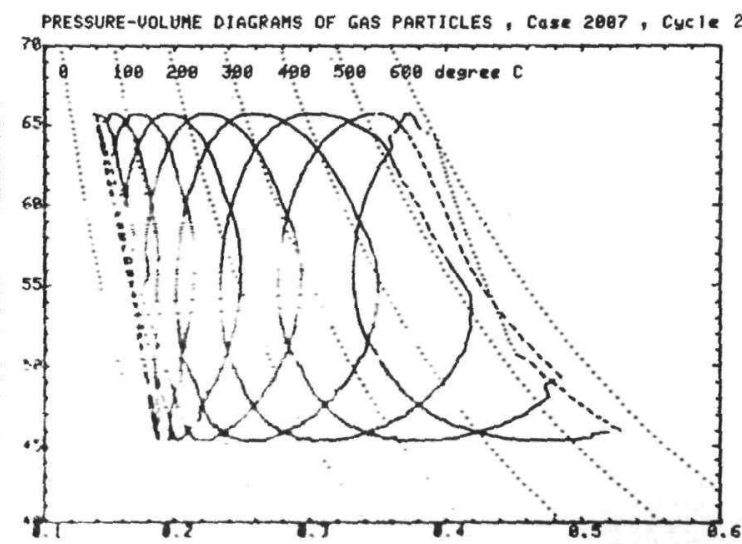

specillic waum, cubic meter der kg

Figure 17 presents pressure-volume diagrams for eight selected gas particles. The volume plotted is the spectif volune of each gas particle. Aga!n, the particles are represented by solld curves while they are in the regenerator, by dashed curves in the heater and cooler, and by dotted curves in the expansion and compression space. In addition, there is a set of (dotted) hyperbolas, representing lines of constant temperature.

The cyclic motion of each particle around its curve is clockwlse, and the area within each loop may be interpreted as the specific work output of each of the particles during the cycle. The figure indicates that most of the power output is produced by a small fraction of the working fluid.
Fig. 18

CYCLIC EHTROPY VARIATION OF GAS PARTICLES, Case 2887 , CYCIE

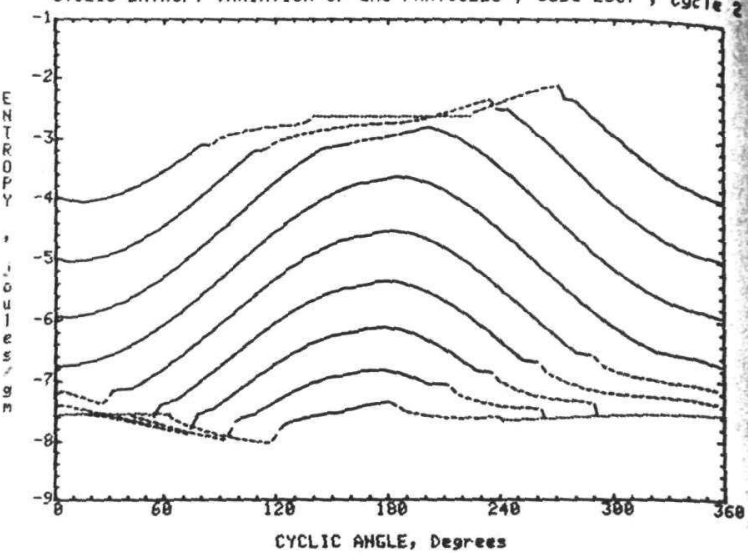

The 1ast two LaGrangian plots presented are Figures 18 and 19. Figure 18 illustrates the cycli entropy variation of the same selected gas particles, and Figure 19 shows the particles' temperature-entropy diagrams. The figures employ the sam solid/dash/dot convention as the previous LaGrangli plots. Note that the dotted curves are close to horizontal (i.e., isentropic), indicating that the expansion and compression nodes are close to adiabatic.

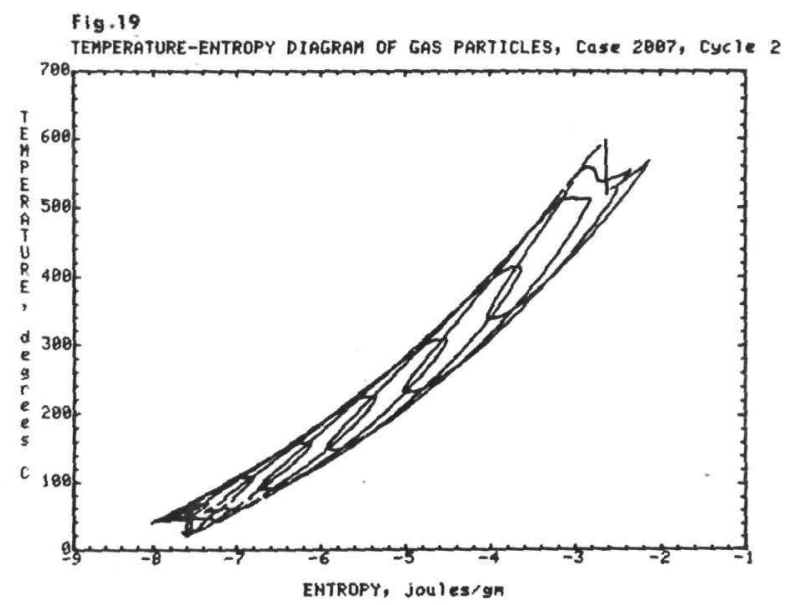

THREE-DIMENSIONAL PLOTS

Previously, Figure 7 presented the variation of gas temperature with cyclic angle, and Figure 8 depicted the variation of gas temperature with nodal position. For added clarity, these two types of plots can be combined in a single, threedimensional (perspective) display, as illustrated by the computer-generated Figures 20 and 21. These were generated using the Graphics Software package developed by the National Center for Atmospheric Research.

Figure 20 displays the cyclic variation of gas temperature as a function of nodal position and of cyclic angle for a typical problem. In addition to the gas temperatures, the temperatures of the heater wall $\left(\mathrm{T}_{\mathrm{H}}\right)$ and cooler wall $\left(\mathrm{T}_{\mathrm{C}}\right)$ are also shown, for reference. The dotted curves represent isotherms corresponding to those two temperatures, and the areas enclosed by those isotherms shows the anomalous region where the 
gas is cooled by the heater wall or heated by the cooler wall.

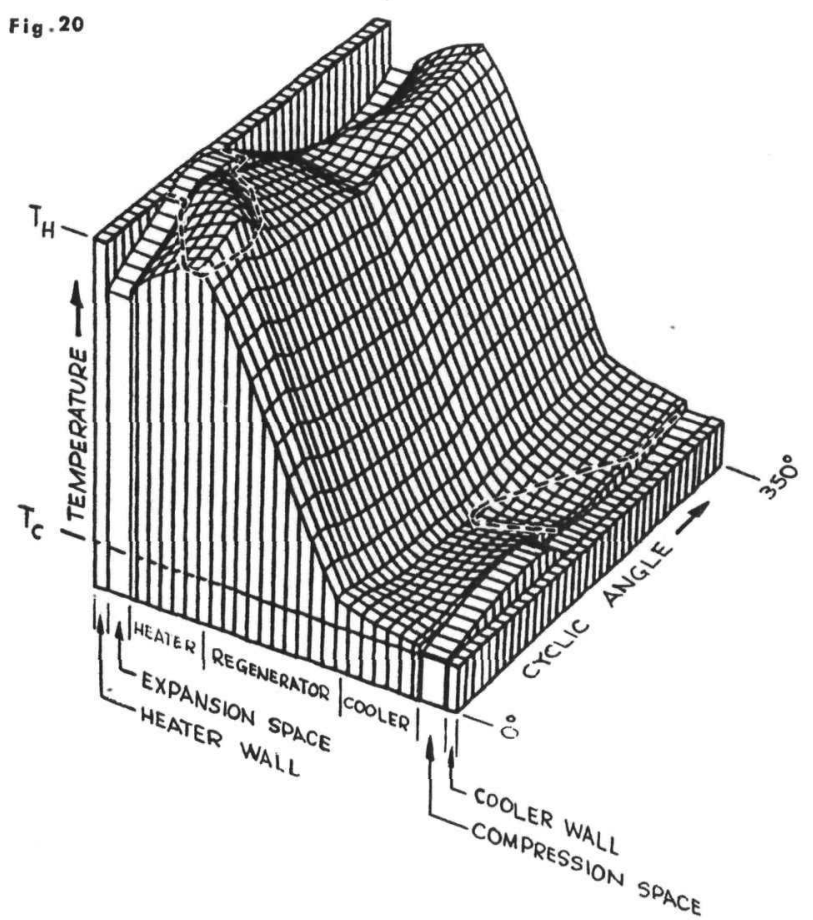

Finally, the three-dimensional plot of Figure 21 presents an even fuller picture, since it also shows the variation of gas volume with time. Here gas temperatures are plotted versus cyclic angle and nodal volumes. All node volumes are constant, except for the expansion space and compression space. These vary sinusoidally as the result of piston motions. The dashed lines indicate the time of local flow reversal, and the two arrows Indicate the flow direction between flow reversals.

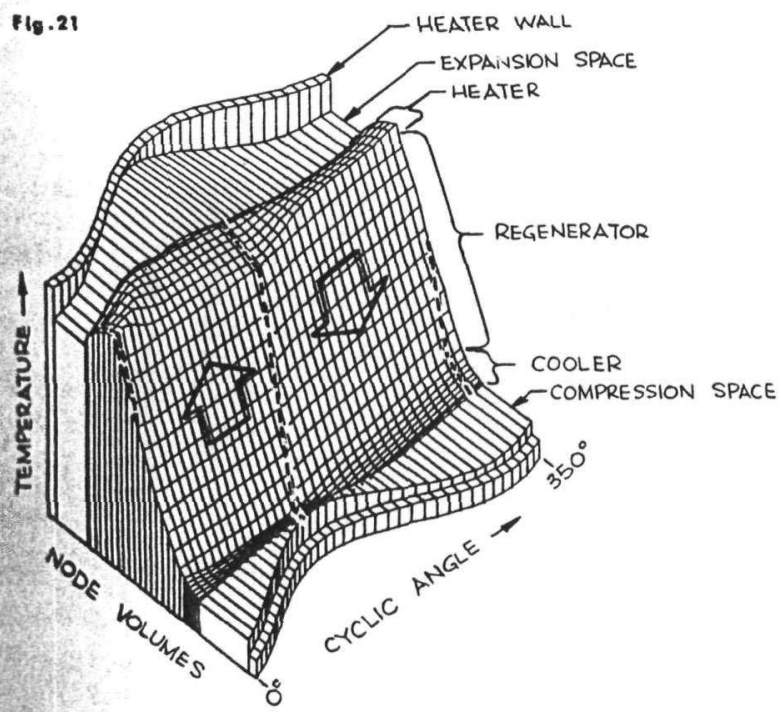

Thus, Figure 21 provides a combined illustration of the effect of piston motions and resultant volume variations on gas flow direction; the effect of expansion and compression on gas temperatures, particularly in the almost adiabatic expansion and compression spaces; and the effect of flow reversals on the instantaneous gas temperature profiles, particularly in the heater and cooler.

\section{CONCLUSION}

The program described and illustrated in this report provides a versatile and, $1 \mathrm{t}$ is hoped, useful tool for the analysis of cyclic thermodynasis machines. It should be readily adaptable to othe: machine topologies, and to future refinement is the analytical model.

\section{ACKNOWLEDGMENT}

The author takes pleasure in expressing tis appreciation for the assistance of M.B. Eck, M. Mukunda, H. Sookiazian, and E. Vogel, all of Fairchild Industries, in carrying out the abovedescribed work.

\section{References}

1. B.Goldwater and R.B.Morrow,"Demonstration of a Free-Piston Stirling Linear Alternator Power Conversion System,"Proc. 12th IECEC, vol. 2, 1977.

2. A.Schock,"Stirling-Engine Nodal Analysis Program", Report No. FSEC-ESD-217-78/127, Fairchild Space and Electronics Co., Germantown, Maryland, May 1978.

3. T.Finkelstein,"Thermophysics of Regenerative Energy Conversion", Paper 67-216, AIAA 5th Aerospace Science Meeting, 1967.

4. I.Urieli,"A Computer Simulation of Stirling Cycle Machines," Ph.D. Thesis, University of the Witwatersrand, 1977. 